\title{
Manuscript Details
}

Manuscript number

Title
JMPO_2016_342

Improving the ecological efficiency of the bottom trawl fishery in the western Mediterranean: it's about time!

Full Length Article

Article type

\section{Abstract}

The improvement of fishing technology has been detrimental to the sustainability of fisheries, which is particularly clear for the bottom trawl fishery. Reducing its environmental impact is a key point for the development of a more sustainable fishery. The present work analyzed different possibilities to mitigate the impact of gears on the seabed and to increase the efficiency of the bottom trawl fishery of the western Mediterranean. The analysis of three experiments showed that different technical measures can lead to benefits such as the reduction of fishing effort, the improvement of the cost-benefit relation and the reduction of the impact on the seabed. All these measures can reduce the emission of $\mathrm{CO} 2$ into the atmosphere whereas one of them also reduces the impact of bottom trawling on the seabed. After years of studies focused on improving the sustainability of this fishery, it's about time to turn this improvement into reality.

\section{Keywords}

Corresponding Author

Corresponding Author's Institution

Order of Authors fishing impact; fuel consumption; efficiency; gears design; bottom trawl; western Mediterranean

Beatriz Guijarro

Instituto Español de Oceanografía

Beatriz Guijarro, Francesc Ordines, Enric Massutí

\section{Submission Files Included in this PDF}

\section{File Name [File Type]}

Cover_Letter.docx [Cover Letter]

Title_page.docx [Title Page (with Author Details)]

Manuscript.docx [Manuscript (without Author Details)]

Highlights.docx [Highlights]

Tables.docx [Table]

Figures_captions.docx [Figure]

Figure1.tif [Figure]

Figure2.tif [Figure]

Figure3.tif [Figure]

Figure4.tif [Figure]

Figure5.TIF [Figure]

Figure6.TIF [Figure]

To view all the submission files, including those not included in the PDF, click on the manuscript title on your EVISE Homepage, then click 'Download zip file'. 
Improving the ecological efficiency of the bottom trawl fishery in the western Mediterranean: it's about time!

Beatriz Guijarro $^{1, *}$, Francesc Ordines ${ }^{1}$ and Enric Massutí ${ }^{1}$

${ }^{1}$ Instituto Español de Oceanografía, Centre Oceanogràfic de les Balears, Moll de Ponent s/n, 07015 Palma de Mallorca, Illes Balears, Spain.

E-mail addresses: beatriz@ba.ieo.es, xisco.ordinas@ba.ieo.es, enric.massuti@ba.ieo.es

*Corresponding author: beatriz@ba.ieo.es 
Improving the ecological efficiency of the bottom trawl fishery in the western Mediterranean: it’s about time!

\begin{abstract}
The improvement of fishing technology has been detrimental to the sustainability of fisheries, which is particularly clear for the bottom trawl fishery. Reducing its environmental impact is a key point for the development of a more sustainable fishery. The present work analyzed different possibilities to mitigate the impact of gears on the seabed and to increase the efficiency of the bottom trawl fishery of the western Mediterranean. The analysis of three experiments showed that different technical measures can lead to benefits such as the reduction of fishing effort, the improvement of the cost-benefit relation and the reduction of the impact on the seabed. All these measures can reduce the emission of $\mathrm{CO}_{2}$ into the atmosphere whereas one of them also reduces the impact of bottom trawling on the seabed. After years of studies focused on improving the sustainability of this fishery, it's about time to turn this improvement into reality.
\end{abstract}

Keywords: fishing impact; fuel consumption; efficiency; gears design; bottom trawl; western Mediterranean.

\title{
1. INTRODUCTION
}

During the last century, the improvement in fisheries technologies (more efficient vessel design, more powerful engines, mechanization of fishing operations, vessel positioning systems, echo-sounders and radar, among others) has increased the fishing capacity of fleets. In most cases these technical improvements have been detrimental to the sustainability of fisheries due to the fact that most of the fishing fleets became overcapitalized [1]. This fact would have led to a decline in the proportion of assessed marine fish stocks exploited within biologically sustainable levels, from $90 \%$ in 1974 to $71 \%$ in 2011, when $29 \%$ of fish stocks were estimated as fished at a biologically unsustainable level and, therefore, overfished [2]. Reducing fishing mortality (F) is a key point to enhance the state of exploitation of marine resources. Fleet reduction and limits in time at sea are some of the direct measures that can be applied to reduce F, although other indirect options, such as catch limits or changes in mesh regulation, are also applicable measures to take into account. In fact, there is not a single way of regulating fisheries and successful programs of fisheries management would involve a mix of direct and indirect fishing effort regulations and other technical conservation measures [3].

The ecosystem approach to fisheries (EAF) is a widely accepted concept in the field of fisheries assessment and management, and it has been proposed as the way forward to reach more sustainable fisheries. The goals of EAF include social, economic and ecological aspects, but a central focus is reconciling the short-term need for catches with the long-term need for sustainability of target species, other ecosystems components and fisheries itself [4]. Advances in fishing gear technology, including selectivity improvements and the development of gears that reduce the environmental impact, that would allow to mitigate some of the unwanted effects of fishing, are essential to the achievement of an environmentally responsible fishing, which is essential to the implementation of the EAF [5, 6].

The environmental impacts of fishing activities are well known. Besides the direct and indirect impacts on target and non-target species, habitats, trophic webs, and biological and functional diversity, the emission of $\mathrm{CO}_{2}$ into the atmosphere by means of fuel consumption should not be 
overlooked. Tyedmers et al. [7] estimated that fisheries globally burned almost 50 billion liters of fuel in the process of catching 80.4 million tons of reported landings, and directly emit 130 million tons of $\mathrm{CO}_{2}$ into the atmosphere at an average rate of 1.7 tons of $\mathrm{CO}_{2}$ per ton of live-weight landed product. These authors estimated that fisheries globally represent approximately $1.2 \%$ of total global oil consumption and the energy content of the fuel burned by global fisheries is 12.5 times greater than the edible-protein energy content of the resulting catch.

Among the wide variety of fishing techniques currently practiced, trawling is one of the most widespread fishing methods used in the world. Bottom trawling has been identified as the fishing activity with the greatest environmental impact, including the most unwanted seabed habitat loss and fragmentation [8,9]. Moreover, the bottom trawl boats are among the most fuel-demanding fishing vessels [10] and bottom trawl targeting crustaceans have been identified as one of the least energyefficient fisheries in the world [11]. Hence, increasing the environmental sustainability and fishing efficiency of this type of fishing activity involves the improvement of its selectivity and the reduction of both, the impact on the seabed and the fuel consumption.

In this sense, the Green Paper aimed at stimulate a debate and to elicit views on the future Common Fisheries Policy (CFP), recognized that "crucial challenges such as climate change, emission policies and energy efficiency must be factored in when defining the future CFP and its role in shaping the future of the fisheries and aquaculture sector". The requirement to reduce fossil fuel consumption and the emission of $\mathrm{CO}_{2}$ into the atmosphere, the need of improving energy efficiency of animal production systems and the continued increase in oil prices (currently, fuel costs represent in average $55 \%$ of the total running costs of fishing fleets) suggests that fuel consumption should be considered not only a current environmental but also an economic problem of fisheries. A fact highlighted in the Green Paper regarding the public financial support is that "it has been estimated that the cost of fishing to the public budgets exceeds the total value of the catches. In simple terms, this means that European citizens almost pay for their fish twice: once at the shop and once again through their taxes”. To tackle this profits/costs ratio problem will strongly depend on the possibility to reduce energy consumption, as far as increasing the amount of catch is not a presumable scenario and fishermen's possibilities to influence the prices is kept low [12].

Due to the EU restrictions of public funding for new vessels construction, the opportunities to reduce fuel consumption are mainly linked to modifications in vessel operation routines and the development of innovative fuel-efficient gears, rather than commissioning new energy-saving vessels. The strategy to analyze innovative improvements should consist in comparing traditional designs with new ones operating under full scale commercial conditions [12]. Experimental sea trials in Portuguese coastal fish trawlers demonstrated that the percentage of fuel consumed in navigation is substantially lower compared to trawling (24\% of the whole fishing trip), being this the most important phase for fuel reduction effects [10]. These authors demonstrated fuel reduction of up to $18 \%$ with simple changes at the trawl level (steeper cuttings in the wings and bellies, and mesh size increases in the respective net sections).

The objective of this paper is to show different ways to mitigate the impact of gears on the seabed and to increase the efficiency of the bottom trawl fishery of the western Mediterranean, by improving the selectivity (and thus indirectly reducing fishing mortality) and reducing the fuel consumption in comparison to the traditional gears. Data coming from three different pilot projects, with sampling based on the modification of fishing operations and/or the trawl gear design, were used. The first experiment (EXP1) consisted in changing the vessel operation, from the usual discontinuous work during five daily trips of 12-16 hours per week, to a continuous work during 46 hours per week. In the other two experiments, the traditional bottom doors were replaced by two types of doors: (i) bottom 
doors more hydrodynamic and lighter (EXP2); and (ii) mid-water doors not touching the seabed (EXP3). Additionally, in EXP2 the sweeps were shortened and the net was replaced by an experimental lighter net, with larger meshes and thinner twine in the wings and square. In EXP1 and EXP2, the change from diamond to square $40 \mathrm{~mm}$ nominal size in the mesh shape of the codend was also assessed.

\section{MATERIAL AND METHODS}

\subsection{EXP1: Change of vessel operation routine}

This experiment was conducted at the Gulf of Lions (north-western Mediterranean), from $24^{\text {th }}$ October to $18^{\text {th }}$ December of 2007, on board two commercial bottom trawlers with similar characteristics: F/V Berto (length 27.3 m, 138 grt, nominal engine power 473 hp) and F/V Sort de Taranet (length 24.4, 126 grt, nominal engine power $540 \mathrm{hp}$ ). These vessels used to operate on slope fishing grounds, located between 70 and $100 \mathrm{~nm}$ far from their harbor, El Port de la Selva (Figure 1). The normal activity of the trawl fishing fleet of this port, and most of the Spanish ports in the Mediterranean, consists in 12 hours duration daily trips from Monday to Friday, with 48 hours of weekly rest (Saturday and Sunday). In some ports, additional time is authorized to reach distant fishing grounds. That is the case of El Port de la Selva, where the activity of the bottom trawl fleet is from 06:00 to 18:00 on Wednesday, Thursday and Friday, when the fleet operates not farther than $~ 50 \mathrm{~nm}$ from El Port de la Selva, and from 02:00 to 18:00 on Monday and Tuesday when the fleet can reach the international waters of Gulf of Lions, placed at more than $70 \mathrm{~nm}$ away from that harbor.

The experiment was developed during 8 fishing trips, and consisted in working continuously a maximum of 46 hours per week, from 02:00 a.m. on Monday to 12:00 midnight on Tuesday, the vessels remaining in port the rest of the week. The type of net used during the experiment was the same, a "cuadrado/dragón"-type of $75 \mathrm{~m}$ headline and $110 \mathrm{~m}$ footrope of polyamide (PA) in the wings and belly and polyethylene (PE) from the funnel to the cod-end, which is routinely used by the

commercial fleet in the area. This net was linked by $50 \mathrm{~m}$ PE legs ( $\left({ }^{4} 40\right)$ and $150 \mathrm{~m}$ steel and

polypropylene (PP) sweeps ( ()$^{44)}$ to metallic bottom doors MAPSA model EXPLORER 1300 (4 m²

and $900 \mathrm{~kg}$ ) and to steel warp ( $) 16$. The two vessels carried out parallel hauls, one vessel using a

'traditional' (in force at the time of the experiment) diamond $40 \mathrm{~mm}$ nominal mesh size cod-end, the other one using a square $40 \mathrm{~mm}$ nominal mesh size cod-end of $3 \mathrm{~mm}$ twine thickness. The two vessels interchanged the nets after each fishing trip. Two different bathymetric strata were sampled, according to the target species of the bottom trawl fishery in the area: (i) upper slope (300-500 m depth), where the target species is Norway lobster (Nephrops norvegicus); and (ii) middle slope (500-700 m depth), where the target species is red shrimp (Aristeus antennatus). The average speed of trawls in both depth strata was 3.1 knots. The SIMRAD trawl monitoring ITI system was used to estimate the arrival and departure of the gear to the bottom, the distance between the doors, and the horizontal and vertical opening of the net. A total of fifty valid samples were carried out ( 25 with the F/V Berto and 25 with the F/V Sort de Taranet).

The daily sale bills were used to obtain additional data of landings and revenues during the experiment and also for the same period during the previous year (October-December 2006), in which vessels developed their usual work (5 days per week and 12-16 hours per day). The total fuel consumption and its cost were also compiled for both periods. 


\subsection{EXP2: Use of more hydrodynamic bottom-doors and a lighter gear}

This experiment was conducted on traditional fishing grounds off southern Mallorca (Balearic Islands; Figure 1) from $14^{\text {th }}$ October to $30^{\text {th }}$ December of 2008, on board the commercial bottom trawler F/V Punta des Vent (length 22.5 m, 55 grt, nominal engine power 365 hp, harbored in Palma). The experiment consisted in working with two trawl gears, which were changed weekly. The first gear was a traditional "tangonera"-type net (900 kg estimated weight), mostly used by the bottom trawlers in the area, with a diamond $40 \mathrm{~mm}$ nominal size mesh codend. This net was linked by $40 \mathrm{~m}$ PP and hemp legs, with Dyneema and steel in the upper ( ()$\left.^{20}\right)$ and lower ( $\left(\varsigma^{46)}\right)$ part, respectively, and $360 \mathrm{~m}$ steel and polypropylene (PP) sweeps ( ()$\left.^{43}\right)$ to metallic oval-shaped bottom doors HIP-SE $(2.66 \times 1.55 \mathrm{~m}=$ $4.1 \mathrm{~m}^{2} ; 670 \mathrm{~kg}$ ) and to steel warp ( $(14$. The second gear was an experimental net, based on the previous one, but lighter (800 kg estimated weight), because the thinner netting and the wider mesh openings, with a square $40 \mathrm{~mm}$ nominal size mesh cod-end of $3 \mathrm{~mm}$ twine thickness. This net was linked by 40 m PP and hemp legs, with Dyneema and steel in the upper ( ()$\left.^{20}\right)$ and lower ( ()$\left.^{46}\right)$ part, respectively, and $310 \mathrm{~m}$ steel and polypropylene (PP) sweeps ( ()$\left.^{43}\right)$ to metallic bottom doors MAPSA model EXPLORER S1150 (2.15x1.40 m= 3.01 m²; $588 \mathrm{~kg})$ and to steel warp ( $) 14$.

The experiment covered three bathymetric strata: (i) deep shelf (80-200 m depth), where the target species is hake (Merluccius merluccius); upper slope (300-500 m depth), where the target species is Norway lobster and (iii) middle slope (500-700 m depth), where the target species is red shrimp. The average speed of trawls was 2.5 knots. A total of 46 daily fishing trips of 12 hours were made, within the normal commercial activity of the trawl fishing fleet in the study area. A total of 20 and 23 valid hauls were done using the traditional and experimental gear, respectively. The SCANMAR system was used to estimate distance, angles and tension of the doors, horizontal and vertical opening of the net, trawl symmetry and water inflow at three different sites of the net (flotsam, funnel and cod-end). The fuel consumption during the fishing trips was estimated using a flow-meter installed in the engine.

\subsection{EXP3: Use of mid-water doors not touching the seabed}

This experiment was conducted from $4^{\text {th }}$ April to $18^{\text {th }}$ May of 2011, on board the commercial bottom trawler F/V Nueva Joven Josefina (length 21.0 m, 44 grt, nominal engine power 150 hp). This vessel, based on Maó, operates on traditional fishing grounds off the eastern and south-eastern Menorca (Balearic Islands; Figure 1). Two different gears were used during this experiment. The traditional gear used consisted in a "semi/tangonera"-type net, with a square $40 \mathrm{~mm}$ nominal size mesh cod-end of 3 $\mathrm{mm}$ twine thickness. The resistance of this net during the fishing operation was estimated around 3575

kg, according to the following expression: $R_{\text {net }}=\frac{8 \times a \times b v^{2} \times \varnothing}{I}$; where $a$ was the fishing circle (39.7 $\mathrm{m}), b$ the length of the net without cod-end $(61 \mathrm{~m}), v$ the trawling speed (2.5 knots), $\varnothing$ the average diameter of netting $(1.7 \mathrm{~mm})$ and $L$ the mean mesh opening $(83 \mathrm{~mm})$. This net was linked by $300 \mathrm{~m}$ steel and polypropylene (PP) sweeps (690 kg weight and $385 \mathrm{~kg}$ resistance) to Thyborøn type 4 doors, commonly used by the bottom trawler. These doors, with a spreading force of $564 \mathrm{~kg}$, estimated from their area $\left(2.92 \mathrm{~m}^{2}\right)$ and weight (550 kg), work in contact to the bottom, with an angle of $30-35^{\circ}$ and have a resistance of $282 \mathrm{~kg}$. The experimental gear used the same components except for the doors 
which were the Thyborøn type 15VFS with a spreading force estimated of $562 \mathrm{~kg}$ ( $2.00 \mathrm{~m}^{2}$ and 340 $\mathrm{kg}$ ). These doors work at some meters above the bottom, with an angle of $27.6^{\circ}$ and a resistance of 121

$\mathrm{kg}$. The linking between the doors and the sweep were made by a steel warp ( $(/ 15)$ of $50 \mathrm{~m}$ length, with in-line chain ballast weighing $175 \mathrm{~kg}$ to ensure an optimal contact of sweeps and net to the bottom.

This experiment covered two bathymetric strata: (i) deep shelf (120-160 m depth), where the target species is hake and (ii) middle slope (500-700 $\mathrm{m}$ depth), where the target species is red shrimp. The average speed of trawls in each depth strata was 2.9 in the deep shelf and 2.2 knots in the middle slope. A total of 21 daily fishing trips (12 hours at sea) were made. Each day 1 or 2 hauls were performed, accounting for 19 and 18 hauls with the traditional and the experimental gears, respectively. During this experiment the SIMRAD trawl monitoring ITI system was used to estimate the arrival and departure of the gear to the bottom, the distance between and the doors and their depth, and the horizontal and vertical opening of the net. The fuel consumption during the fishing trips was estimated using a flow-meter installed in the engine.

\subsection{Data analysis}

In all the experiments, after each haul, the crew and the scientific team sorted the catches in the codend according to taxonomic and commercial categories (landings and discards), and then these categories were counted and weighed separately. Size composition of the catches was also obtained, although this information was no analyzed here as plenty information on size selectivity in the western Mediterranean is already available [13-18].

Differences on gear behavior and geometry among gears were tested for each experiment with a Student t-test. Redundancy analysis (RDA) was used to investigate differences in catch composition (in terms of individuals or kg per hour) among factors (vessel and mesh shape in the cod-end for EXP1, and type of gear for EXP2 and EXP3) in each bathymetric stratum. Monte Carlo freedistribution permutation based test was used to test the significance of each factor. Only those species with a frequency of appearance greater than $15 \%$ were included in this analysis. Bi-plot diagrams were produced to represent the ordination of variables and factors. For each experiment and in each strata, the average yield of the total catch, landings and discards, and the main commercial and/or ecological species was estimated by factor, in terms of number and weight per effective hour of trawl (from arrival to departure of the net to the bottom). Two-way analysis of variance (ANOVA) was used to check for differences between factors.

The Student t-test was used to compare fuel efficiency in all the experiments. For EXP1, fuel cost in relation to the first sale value $(\% €)$ and daily fuel consumption in relation to the first sale value $(1 / €)$ were compared between the period in which the experiment was carried out and the same period in the previous year. For EXP2 and EXP3, the variables analyzed were fuel consumption by hour $(\mathrm{l} / \mathrm{h})$ and the efficiency during the effective fishing time in relation to the first sale value (l/€). In EXP2 and EXP3, this comparison were done by bathymetric strata, but not in EXP1 as the information was available by fishing trip and not by haul. Additionally, the records of daily fuel consumption of the bottom trawler which carried out EXP3 between April 2008 and December 2014, facilitated by the boat skipper, were used to plot the evolution of quarterly mean daily fuel consumption. Moreover, the fuel consumption and official daily sales bills of the dwarf in 2009 and 2012 were used as before/after comparisons of monthly mean daily fuel consumption and efficiency (l/€) between a period in which no fuel saving measure had been undertaken in the boat (2009) and a period immediately after all the saving measures undertaken had been fully implemented (reduction of boat speed when sailing to fishing grounds, change of gears netting, and use of mid-water doors). This analysis was restricted to 
months from March to December in which the required data was available for both years (January and February corresponded to holiday periods in 2009 and 2012, respectively). Comparisons between 2009 and 2012 were carried out using the Student t-test. Prior to the use of any parametric analysis, the assumptions of normality and homogeneity of variance of the data were checked, and when not met, data was log or square-root transformed [19].

\section{RESULTS}

\subsection{EXP1}

The mean vertical opening of the net ranged between 3.3 and $4.6 \mathrm{~m}$, while door spread from 86 to 93 $\mathrm{m}$ (Table 1a). Taking into account that distance between doors and the wing end of the net was $200 \mathrm{~m}$, the horizontal opening of the net could be estimated at around 28-32 m.

Significant differences by mesh type were only detected in the upper slope for the total abundance and discarded abundance, with higher values with diamond mesh (Table 2a). No significant differences were attributable to neither mesh type nor vessel in the middle slope. RDA showed significant differences between mesh shape in the discards abundance composition, both in the upper and middle slope, with the model explaining around $10 \%$ of the variance (Figure 2). The species that showed significant larger abundances with diamond mesh with respect to the square mesh in the upper slope were Gadiculus argenteus (272 vs. 48 individuals/h, respectively), Hymenocephalus italicus (10 vs. 2 individuals/h, respectively) and Phycis blennoides (49 vs. 6 individuals/h), while Polycheles typhlops, Etmopterus spinax and H. italicus showed larger abundance with diamond (17, 49 and 25 individuals/h, respectively) than with square mesh (1, 14 and 1 individuals/h, respectively) in the middle slope. The only differences in the commercial catch composition were detected between vessels, with the RDA explaining 9\% of the variance, and not between mesh shapes (Figure 2, Table 2a). At species level, with larger abundance indices were found with F/V Sort de Taranet with respect to F/V Berto for Molva macrophthalma (2 vs. 1 individuals/h, respectively) and Trygla lyra (17 vs. 10 individuals/h, respectively).

In this experiment, the fuel cost in relation to the first sale value showed a reduction of $67-77 \%$ for both vessels (Table 3a). Similarly, the fuel consumption in relation to the first sale value also showed a reduction of the same order between the periods analyzed (Table 3a).

\subsection{EXP2}

In this experiment, some differences between the traditional and experimental gears were detected in relation to their behavior and geometry (Table 1b). The doors used in the experimental gear worked at higher distance than those traditionally used, with differences of 13 and 8-9 $\mathrm{m}$ on deep shelf and slope, respectively, in spite of demanding a reduction of warp length of $100 \mathrm{~m}$ in all the bathymetric strata surveyed. The experimental doors also showed lesser tension, with mean differences of 293, 43 and 71 $\mathrm{kg}$ on the deep shelf, upper slope and middle slope, respectively, and lesser roll (between $1^{\circ}$ and $6^{\circ}$ ) and pitch $\left(\sim 0.6^{\circ}\right)$ angles, with respect to the traditional doors. The horizontal opening of the net was larger using the experimental gear than using the traditional one (from $1.9 \mathrm{~m}$ on the deep shelf to $3.5 \mathrm{~m}$ on the middle slope). Small differences $(0.1 \mathrm{~m})$ were also observed for the vertical opening. Trawl symmetry values were good with both gears, with values lower than $1^{\circ}$. Water flow values were in general equal or higher with the experimental gear.

The only significant differences were found by mesh type in the abundance for the upper slope, for commercial, discarded and total catch, being the abundances higher with the traditional gear (Table 2b). Similarly, RDA only showed significant differences between gears in the abundance composition 
obtained on the upper slope, both in the commercial and the discarded catch, with the models explaining 12-18\% of the variance (Figure 3). At specific level, Lepidorhombus boscii and Plesionika giglioli showed larger indices of commercial catch with the traditional gear (43 and 34 individuals/h, respectively) than with the experimental one (23 and 4 individuals/h, respectively). In the discarded catch, Scyliorhinus canicula, G. argenteus, H. italicus and Plesionika heterocarpus showed larger abundance indices with traditional gear than with the experimental one: 46 vs. 4, 327 vs. 32, 50 vs. 2 and 36 vs. 7 individuals/h, respectively.

In this experiment, fuel consumption by hour (l/h) showed a reduction of 5 and $11 \%$ in the upper and middle slope, respectively (Table 3b). An improvement in the efficiency was detected in the deep shelf, as the ratio $1 / €$ showed a significant decrease of $38 \%$.

\subsection{EXP3}

In this experiment, the mean height of the mid-water doors over the seafloor was $3.4 \mathrm{~m}$ on the deep shelf and $5.8 \mathrm{~m}$ on middle slope, ranging between 0.7 and 9.5 , and 2.9 and $8.8 \mathrm{~m}$, respectively. Trawl geometry during this experiment showed some significant differences between gears in both depth strata surveyed (Table 2c). On the deep shelf, two of the three parameters compared showed higher values using the mid-water doors than using the traditional ones working in contact to the bottom: door spread of 123 and $98 \mathrm{~m}$, respectively, and net vertical opening of 1.6 and $1.3 \mathrm{~m}$, respectively. By contrast, horizontal opening did not show significant differences between both gears, with values around 23-24 m. On the middle slope, the horizontal and vertical openings of the net did not show significant differences (around 29-30 m and 3.3-3.4 m, respectively), whereas the door spread using mid-water doors was larger than using the traditional ones: 169 and $125 \mathrm{~m}$, respectively. Maneuvers on the deck with the experimental gear did not represent any backward or extra effort of the crew, neither the adaptation of any component on the deck.

The abundance for commercial species was significantly different by gear, both in the deep shelf and upper slope, as well as the total catch in the middle slope (Table 2c), the highest values obtained with the bottom doors. In the deep shelf, RDA showed significant differences by gear in the abundance and biomass of the commercial catch (Figure 4, 23\% of variance explained), with depth being also significant for this fraction (9\% of variance explained) as well as for the discards. At species level, catch yields of Mullus barbatus, S. canicula and Trachurus trachurus were higher using mid-water doors than using the doors working in contact to the bottom (e.g. 2.8 vs. 1.2, 3.7 vs. 2.6 and 3.1 vs. 0.7 $\mathrm{kg} / \mathrm{h}$, respectively), whereas catches of Chelidonichthys cuculus, Glossanodon leioglossus, Trigla lyra, Merluccius merluccius and Zeus faber were higher using the doors working in contact to the bottom than using mid-water doors (e.g. 38 vs. 22, 170 vs. 26, 10 vs. 5, 40 vs. 14 and 5 vs. 1 individuals/h, respectively). On the middle slope, RDA showed significant differences by gear both for the commercial and discarded abundances and biomasses (Figure 4, 17-25\% of variance explained). At specific level, Aristeus antennatus catch yields were higher with the bottom doors than with the midwater doors in terms of abundance (13 vs. 11 individuals/h, respectively), while the contrary in terms of biomass (865 vs. $1147 \mathrm{~kg} / \mathrm{h}$, respectively). Micromesistius poutassou and Geryon longipes showed higher catch yields with the mid-water doors than with the bottom doors, in terms of abundance (1.2 vs. 0.3 and 0.7 vs. 0.2 individuals/h, respectively), while the contrary was observed in terms of biomass (2.3 vs. 8.5 and 2.9 vs. $9.7 \mathrm{~kg} / \mathrm{h}$, respectively).

The fuel consumption by hour showed a significant decrease of $12 \%$ and $5 \%$ in the deep shelf and middle slope, respectively (Table 3c). The mean efficiency during the effective fishing time (l/€) did not show significant differences neither on the deep shelf nor on the middle slope (Table 3c). A clear decrease in quarterly mean daily fuel consumption of the bottom trawler which carried out this experiment can be observed from 2008 to 2014, with three distinguishable periods (2008-2009, 2010- 
2011 and 2012-2014, Figure 5), related to the introduction of different fuel saving measures. First saving measures were implemented in the last quarter of 2009 and consisted in the reduction of boat speed when sailing to fishing grounds and a change of gear netting to low the drag coefficient. After EXP3 (second quarter of 2011), the vessel continued using the mid-water doors, with a period of adjustments in the gear until the current setting were achieved in the first quarter of 2012. These adjustments consisted in a weight reduction of the in-line chain ballast from 175 to $125 \mathrm{~kg}$ and the reduction of the sweeps length, from 300 to $260 \mathrm{~m}$. From 2009 (before the implementation of the first saving measures) to 2012 (the first year in which all saving measures were already in use), the mean efficiency in terms of daily fuel consumption in relation to the first sale value (l/€) value improved from $0.53 \pm 0.01$ to $0.34 \pm 0.01 \mathrm{l} / €$, whereas the mean daily fuel consumption had decreased from $628 \pm 5$ to $463 \pm 4$ l. These differences were consistent throughout the periods compared on a monthly basis (Figure 6). The mean daily fuel saving comparing these two periods was $166 \mathrm{l}$ of fuel, which taking into account the fuel price ( $0.6 € / l$ on average) and considering an average of 220 fishing days per year, represents saving up to $21800 € /$ year.

\section{DISCUSSION}

Bottom trawling has become increasingly controversial in recent years due to its low ecological efficiency, the impact of the different elements of the gear (doors, sweeps and net) on the seabed, the amount of discarded catches and the fuel consumption per fish harvested [20-24]. The challenge, and maybe the only possibility to preserve this fishery, is to achieve a more sustainable activity, both ecological and economically. Measures should aim at allowing harvesting with minimal impact, not only on juvenile fish and non-target species but also on the seabed and benthic habitats [25]. Measures should also aim at minimizing the impact in the marine environment and also in the entire ecosystem [10], reducing the emission of $\mathrm{CO}_{2}$ into the atmosphere by means of reducing the fuel consumption, which would also improve the economic efficiency of this fishery.

A reduction of discards with the square mesh cod-end has been found in the upper and middle slope during EXP1 and EXP2, in which the comparison between $40 \mathrm{~mm}$ diamond and square mesh cod-ends were made. This was mainly due to the decrease in discarded abundance of small-sized noncommercial species in the Gulf of Lions (EXP1) and of small individuals of the demersal elasmobranches Scyliorhinus canicula and Galeus melastomus in the Balearic Islands (EXP2). This last result is particularly important, because the Balearic Archipelago is one of the areas in the western Mediterranean with higher diversity and density of these vulnerable species [26-28]. These results confirm those already obtained in the western Mediterranean, which showed an improvement of the trawl selectivity with this shape modification, without a change in the catch composition or a reduction in the commercial yields of main target species $[13,14,16,29]$. The fact that in the present experiments no covers were used over the cod-end, as done in previous studies, allowed to analyze our results without the potential disadvantages of using cover, as alteration of the geometry of the net and its filtering, which could affect the behavior and escape of fishes, thus providing less-than accurate information on the selectivity and catch efficiency under normal commercial conditions [30,31].

The improvement of size selectivity has been proposed as the best way to restore the overfished stocks of the Mediterranean, which represent $85 \%$ of the assessed stocks, because a simple reduction in the current fishing mortality towards an MSY reference value, without any change in the fishing selectivity, will allow neither stock biomass nor fisheries yield and revenue to be maximized [32]. 
According to these authors improving gear selectivity would also contribute to restore marine ecosystem structure and resilience to enhance ecosystem services, such as reservoirs of biodiversity and functioning food webs. In addition, since Sardà et al. [33] the new obligation to land discards in European Seas, especially in their southern ecosystems such as the Mediterranean, must be reached by reducing discarding at source, not by promoting their landing. Our results and the above mentioned previous studies have demonstrated that the use of $40 \mathrm{~mm}$ square mesh cod-end in the bottom trawl can contribute to this. However, the replacement of the $40 \mathrm{~mm}$ diamond mesh cod-end by a $40 \mathrm{~mm}$ square mesh cod-end, established in the Council Regulation (EC) N 1967/2006, of 21 December 2006, concerning management measures for the sustainable exploitation of fishery resources in the Mediterranean Sea, was not implemented until 2010, and more than $90 \%$ of vessels adopted the exceptional use of the $50 \mathrm{~mm}$ diamond mesh cod-end also included in this regulation [34]. Although this exception was only contemplated in case of the acknowledged size selectivity with $50 \mathrm{~mm}$ diamond mesh cod-end was equivalent to or higher than that of $40 \mathrm{~mm}$ square mesh cod-end, there is a lack of scientific information about the selectivity of $50 \mathrm{~mm}$ diamond mesh cod-end in the western Mediterranean to support that, so this exception should not had been approved.

The change in vessel operation assessed in EXP1 has shown a way to improve the cost-benefit relation of the bottom trawl fishery. The reduction in the weekly activity of the vessels, from 68 hours discontinuous (12 hours/day during 5 days/week) to 46 hours continuous, did not show differences in the commercial landings. However, the effective fishing effort would be reduced. The maximum effective trawling time could be estimated in 5-6 hauls and 18 hours per weekly fishing trip, which represents less fishing time than the allowed with the current regulation, estimated in 4-6 hours in each of the 5 daily fishing trips authorized per week (20-30 weekly hours). This implies not only an increase in the fishing efficiency, by reducing the operating costs with similar landings, but also in the ecological efficiency, because of the reduction of $\mathrm{CO}_{2}$ emissions due to the savings in weekly fuel consumption. Last but not least, the reduction of the weekly activity can improve the life quality of the crew, an important aspect, taking into account the difficulties of the fishing sector to offer attractive jobs for young people in coastal communities during the last decade, one objective of the future CFP.

However, this change in the vessel operation could potentially have negative effects for marine ecosystem of the western Mediterranean, without the adequate additional management measures. Longer fishing times will make un- or low-exploited fishing grounds accessible to the trawl fishery. Although there is no information on the estate of exploitation of the demersal resources dwelling the open slope of the Gulf of Lions, some populations parameters of the species captured in the surveyed area showed apparent better state that heavy exploited areas in the vicinities of the fishing ports, which are considered as overfished, both at stock [35-37] and ecosystem level [38-40]. The Gulf of Lions is one of the areas with the highest number of submarine canyons in the Mediterranean [41]. These geomorphological structures are considered as essential habitats for some species, as they can act as recruitment areas for deep sea fish and crustaceans [42,43], including A. antennatus [44]. Farrugio [45] considered the submarine canyons of the Gulf of Lions are vital to protect "cryptic populations" of adult of hake (M. merluccius) and most probably for other important demersal species, and emphasized the recommendation by Froese [46] "let the mega-spawners live”, ensuring long life for a non-exploited spawning fraction of the stock, as the best guarantee against the risk of its overexploitation. The submarine canyons have been listed as sensitive habitats [47], being also important areas from an ecological point of view [41], where white coral communities form highly diverse 
tridimensional habitats, including both benthic (sponges, echinoderms and hydrozoa) and nektonic species (crabs and fish). In fact, the area surveyed in EXP1 is now part of a Fisheries Restricted Area recommended by the General Fisheries Commission for the Mediterranean (GFCM) to protect spawning aggregations and deep sea sensitive habitats [45]. Management measures like this adopted by the GFCM, jointly with the current systems for tracking and monitoring remotely the activities of fishing vessels, could prevent the potential negative effects of a change in the vessel operation of the western Mediterranean bottom trawl fishery.

In EXP2, the change of the doors and the use of a lighter gear implied shorter warp needs, better door hydrodynamics, less door friction and, globally, less tension and higher filtration in comparison to the traditional gear, and a consequent reduction of fuel consumption during the effective fishing time. However, despite these improvements should also yield a potential reduction of the direct impact of the gear on the seabed (lower weight, azimuth and elevation angles of the doors; lower weight of the net and a $50 \mathrm{~m}$ reduction of sweeps' length), the increase of the doors opening is a negative aspect that should be taken into account as it represents an increase of the impacted seabed surface. Doors and sweeps herd the fish towards the trawl mouth of the bottom trawl [48]. The sweeps skim the seafloor when dragged and doing so, account for a large part of the negative effects of trawling on the seabed [49]. Hence, to take advantage of the potential impact decrease achieved by using the experimental doors and net would need further reductions of sweeps' length until reaching a similar door opening, and hence impacted area, than when fishing with the traditional gear used prior to this experiment. It should be also noted that the potential increase of the damages to the seafloor resulting from the increase of the angle of the sweeps in relation to the boat course (i.e. sweeps attacking the seafloor more transversely) remains not assessed.

In EXP3 the substitution of traditional doors dragged through the bottom by mid-water doors allowed a reduction in fuel consumption during the effective time of fishing of $12 \%$ and $5 \%$ on the continental shelf and the slope, respectively. The lower fuel savings when fishing on the slope can be related to the larger length of warp (up to $1700 \mathrm{~m}$ length), whose contribution to the total resistance of the gear probably reduces the proportion of resistance contributed by the doors to the total resistance of the gear. The distance between doors was larger using mid-water doors which could indicate a larger surface being impacted, but it must be considered here that 1) the horizontal opening of the net did not show differences between gears, pointing out that the angle of sweeps was very similar; and 2) the doors were attached to the ballast chain ( $15 \mathrm{~m}$ long) with $50 \mathrm{~m}$ of cable not in touch with the bottom. Therefore, the distance between the beginning of the ballast chains (i.e. the first element after the doors that was in contact with the bottom) was probably similar to distance between traditional doors and supposed only a slight increase of the surface impacted, which was reduced after the experiment (see below). Hence, the use of mid-water doors implies an ecological improvement as their impact on the seabed disappears while the absence of friction with the seabed reduces fuel consumption. However, the fuel saving during EXP 3 did not represent an improvement of the efficiency in terms of fuel consumption in relation to the first sale value, but it must be considered the magnitude of the change in EXP3, by introducing an element that behaves quite differently from the traditional one (doors contacting the bottom). In fact, it took almost five months to the skipper to get the experimental gear as adjusted to the fishery as it was the traditional one. The adjustments included reducing the weight of the ballast chain from 175 to $125 \mathrm{~kg}$ (15 to $11 \mathrm{~m}$ ) and the use of sweeps $50 \mathrm{~m}$ shorter than in the original setting of the experimental gear, hence, reducing the swept area when compared to the traditional gear. All these improvements, along with previous changes already fully implemented at the beginning of the experiment (lower speed when sailing to the fishing grounds and change of gear netting to low the drag coefficient), resulted in an average fuel saving of around 157 l/day (ca. 25\%) 
between the average of 2009, a year before implementation of any saving measure, and the average of 2012, the first year in which all the saving measures, still currently in use by the vessel, had been fully implemented. Previous studies on mid-water doors in western North-Atlantic and northwestern Mediterranean have also shown reductions in fuel consumption between 5 and 20\% [50,51]. There are other simple ways to reduce fuel consumption rather than major changes in overall vessel technology, as demonstrated by Parente et al. [10] in the Portuguese bottom trawl fleet. Fuel saving up to $26 \%$ can be obtained by changing the navigation speed and during the trawling, the most important phase for fuel reduction efforts, and up to $18 \%$ through small changes in the net, as steeper cuttings and mesh size increase in the wings and bellies. More recently, a numerical method for optimization of the cable lengths in trawls (warps, bridles, headline and footrope) predicted that it would be possible to reduce the ratio between the trawl drag and catch efficiency by up to $46 \%$ by optimizing the cable lengths, which would also enable a considerable reduction in fuel consumption [52].

Although the proposed measures in EXP1 (change of vessel operation routine) are very specific to the study area and maybe difficult to extent to other regions, the introduction of lighter gears (EXP2) and mid-water doors (EXP3) are plausible technical measures to be applied in the bottom trawl fishery. They have been demonstrated to be adequate to reduce the impact of bottom trawling on the seabed and the emission of $\mathrm{CO}_{2}$ into the atmosphere. In both cases, the new doors did not show any problem during the manoeuvres and, in fact, both vessels are still using the mid-water doors, several years after the experiment was carried out. The reduction of the emission of $\mathrm{CO}_{2}$ was also obtained with the change in vessel operation (EXP1) in addition to the reduction of the effective fishing effort. All three aspects (impact, effort and consumption) are main challenges for the bottom trawl fishery. These outcomes that can allow the improvement of the ecological efficiency of this fishery have other direct positive consequences in the short term, as the reduction of its operating costs and the improvement of the economic efficiency. This is important to be highlighted, because some measures proposed in the management of fisheries do not show in the short term the expected results that will only be reached in the medium and large term: e.g. improvement of size selectivity in the Mediterranean bottom trawl fishery by using $40 \mathrm{~mm}$ square-mesh in the cod-end [53]. A contradiction that would not favor the acceptance and understanding of new management measures by the fisheries sector and, therefore, their successful implementation.

In spite the advantages of these management measures, it is also necessary to consider potential negative consequences. The modifications in EXP2 represented an increase in the door distance and horizontal net opening, which could imply an increase in the swept area and thus an increase in the effective fishing effort in relation to the traditional gear. Similar consequences could arise by the improvement of net filtering, which allows an increase of the trawling speed. In any case, the implementation of Council Regulation (EC) No 1967/2006, which in its Annex II established that technical specifications limiting the maximum dimension of floatline, groundrope, circumference or perimeter of trawl nets should have been adopted by October 2007, could prevent these potential negative effects. However, this regulation has not yet been applied.

Although the differences found in landings and commercial yields when comparing the traditional and experimental gears assessed have been low or even null, it must be taken into account that some modifications of the gears could also affect their catch efficiency. For instance, sweeps are thought to play a key role in the herding process, as they are designed to keep target fish within the trawl path [54]. The herding properties of the sweeps may be of particular importance when fishing with midwater doors, as the lack of contact between the doors and the seabed means that no sand cloud is created by the sweep section to contribute to the herding. Bottom sweeps are known to be very effective for herding benthic species such as skates and flatfish [55]. Although lifting the doors from the seabed is touted as a positive development for the bottom trawl fleet targeting cod (Gadus morhua) 
in the Barents Sea, fishing with the lifted sweeps led to $33 \%$ of cod catch losses in comparison with the setup that kept the sweeps at the seabed [48].

\section{CONCLUSIONS}

Currently, there is a general growing awareness for "greener" fishing activities and among the fisheries stakeholders of the need to ensure economically balanced fishing companies. The first should be perceived not only in terms of stock sustainability, reduction of by-catches and discards, and seafloor impact of gears, but also in terms of the broader perspective of energy efficiency and vessel emissions [10]. Technology and innovation can assist in mitigating ecological impacts of fisheries [5]. Although the reduction of fishing mortality using direct measures is probably the most applied management measure, the present study has shown than additional measures, such as simple modifications in the vessels operation and the fishing gears can contribute to this objective in the bottom trawl of the western Mediterranean and to reduce the impact of this fishery. Moreover, this type of modifications does not represent a decrease in the revenues and contribute to improve not only the ecological but also the economic efficiency of this fishery, through the reduction of fuel consumption and hence the exploiting costs. However, each specific case should be closely evaluated, in order to select the best combination of management measures to ensure advantages and prevent risks. If fishing industry is closely involved in the formulation of the solutions, the implementation of these actions is then facilitated, as their successful application appears to depend largely on their acceptance but they are difficult and costly to enforce where measures are either misunderstood or unpopular $[3,25,56]$. The tendency to maintain fishing opportunities has to be linked with the longer-term aim of improving sustainability. By providing the correct incentives and defining realistic targets, it should be possible not only to mitigate the fishing direct and indirect impact on marine ecosystems, but also to increase the energetic and economic efficiency of the bottom trawling. The success in fisheries management is possible if the available tools are implemented. For that, management authorities need to develop legally enforceable and tested harvest strategies, coupled with appropriate rights-based incentives to the fishing community, for the future of fisheries to be better than their past [57]. Our results show plausible technical and innovative measures to be applied to the Mediterranean trawling. After so many years of studies focused on improving the sustainability of this fishery, it's about time to turn this improvement into reality.

\section{ACKNOWLEDGEMENTS}

These studies were funded by the Spanish Ministry of Agriculture, Food and Environment (RAI-AP26/2007, RAI-AP-76/2007 and PORTES projects). The authors want to thank to the scientific teams who participate in the sampling at sea and very especially to the owners and crew of the commercial vessels involved in the sampling.

\section{REFERENCES}

[1] D. Pauly, V. Christensen, S. Guénette, T.J. Pitcher, U.R. Sumaila, C.J. Walters, R. Watson, D. Zeller, Towards sustainability in world fisheries., Nature. 418 (2002) 689-695. doi:10.1038/nature01017.

[2] FAO, The State of World Fisheries and Aquaculture 2014, Rome, 2014.

[3] J.R. Beddington, R.B. Retting, Approaches to the regulation of fishing effort, FAO Fish. Tech. Pap. 243 (1984) 1-39. http://www.fao.org/docrep/003/X6858E/X6858E00.htm\#t.

[4] S. Jennings, J. Rice, Towards an ecosystem approach to fisheries in Europe: A perspective on 
existing progress and future directions, Fish Fish. 12 (2011) 125-137. doi:10.1111/j.14672979.2011.00409.x.

[5] P.E. McShane, M.K. Broadhurst, A. Williams, Keeping watch on the unwatchable:

Technological solutions for the problems generated by ecosystem-based management, Fish Fish. 8 (2007) 153-161. doi:10.1111/j.1467-2679.2007.00242.x.

[6] S. Jennings, A.S. Revill, The role of gear technologists in supporting an ecosystem approach to fisheries, ICES J. Mar. Sci. 64 (2007) 1525-1534. doi:10.1093/icesjms/fsm104.

[7] P. Tyedmers, R. Watson, D. Pauly, Fueling global fishing fleets, Ambio. 34 (2005) 635-638.

[8] S. De Juan, S.F. Thrush, M. Demestre, Functional changes as indicators of trawling disturbance on a benthic community located in a fishing ground (NW Mediterranean Sea), Mar. Ecol. Prog. Ser. 334 (2007) 117-129. doi:10.3354/meps334117.

[9] H. Hinz, V. Prieto, M.J. Kaiser, Trawl disturbance on benthic communities: Chronic effects and experimental predictions, Ecol. Appl. 19 (2009) 761-773. doi:10.1890/08-0351.1.

[10] J. Parente, P. Fonseca, V. Henriques, A. Campos, Strategies for improving fuel efficiency in the Portuguese trawl fishery, Fish. Res. 93 (2008) 117-124. doi:10.1016/j.fishres.2008.03.001.

[11] R.W.R. Parker, P.H. Tyedmers, Fuel consumption of global fishing fleets: current understanding and knowledge gaps, Fish Fish. (2014) n/a-n/a. doi:10.1111/faf.12087.

[12] EFTP, Fishing vessel technologies. Challenges for a sustainable European fishing fleet, Capo Granítola, Sicily, 2012.

[13] N. Bahamon, F. Sardà, P. Suuronen, Improvement of trawl selectivity in the NW Mediterranean demersal fishery by using a 40mm square mesh codend, Fish. Res. 81 (2006) 15-25. doi:10.1016/j.fishres.2006.05.020.

[14] B. Guijarro, E. Massutí, Selectivity of diamond- and square-mesh codends in the deepwater crustacean trawl fishery off the Balearic Islands (western Mediterranean), ICES J. Mar. Sci. 63 (2006) 52-67. doi:10.1016/j.icesjms.2005.08.011.

[15] A. Lucchetti, Comparison of diamond- and square-mesh codends in the hake ( Merluccius merluccius L . 1758 ) trawl fishery of the Adriatic Sea ( central Mediterranean ), Sci. Mar. 72 (2008) 451-460. doi:10.3989/scimar.2008.72n3451.

[16] F. Ordines, E. Massutí, B. Guijarro, R. Mas, Diamond vs . square mesh codend in a multispecies trawl fishery of the western Mediterranean : effects on catch composition , yield , size selectivity and discards, Aquat. Living Resour. 338 (2007) 329-338. doi:10.1051/alr.

[17] A. Sala, A. Lucchetti, C. Piccinetti, M. Ferretti, Size selection by diamond- and square-mesh codends in multi-species Mediterranean demersal trawl fisheries, Fish. Res. 93 (2008) 8-21. doi:10.1016/j.fishres.2008.02.003.

[18] F. Sardà, G.Y. Conan, X. Fusté, Selectivity of Norway lobster Nephrops norvegicus (L.) in the northwestern Mediterranean, Sci. Mar. 57 (1993) 167-174.

[19] A. Underwood, Techniques of analysis of variance in experimental marine biology and ecology, in: Oceanogr. Mar. Biol. An Annu. Rev., Aberdeen University Press/Allen \& Unwin, London, 1981: pp. 513-605.

[20] J.B. Jones, Environmental impact of trawling on the seabed: A review, New Zeal. J. Mar. Freshw. Res. 26 (1992) 59-67. doi:10.1080/00288330.1992.9516500.

[21] F. Ziegler, P. Hansson, Emissions from fuel combustion in Swedish cod fishery, J. Clean. Prod. 11 (2003) 303-314.

[22] S. Lokkeborg, Impacts of trawling and scallop dredging on benthic habitats and communities, FAO Fish. Tech. Pap. 472 (2005) 1-58.

[23] J.W. Valdemarsen, J.W. Valdemarsen, T. Jorgensen, T. Jorgensen, A. Engas, A. Engas, Options 
to mitigate bottom habitat impact of dragged gears., 2007.

[24] E. Schau, H. Ellingsen, A. Endal, S. Aanondsen, Energy consumption in the Norwegian fisheries, J. Clean. Prod. 17 (2009) 325-334.

[25] N. Graham, R.S.T. Ferro, W.A. Karp, P. Macmullen, Fishing practice, gear design , and the ecosystem approach - three case studies demonstrating the effect of management strategy on gear selectivity and discards, ICES J. Mar. Sci. 64 (2007) 744-750.

[26] E. Massutí, J. Moranta, Demersal assemblages and depth distribution of elasmobranchs from the continental shelf and slope off the Balearic Islands (western Mediterranean), ICES J. Mar. Sci. 60 (2003) 753-766. doi:10.1016/S1054.

[27] F. Ordines, E. Massutí, J. Moranta, A. Quetglas, B. Guijarro, K. Fliti, Balearic Islands vs Algeria: two nearby western Mediterranean elasmobranch assemblages with different oceanographic scenarios and fishing histories, Sci. Mar. 75 (2011) 707-717. doi:10.3989/scimar.2011.75n4707.

[28] S. Ramírez-Amaro, F. Ordines, B. Terrassa, A. Esteban, C. García, B. Guijarro, E. Massutí, Demersal chondrichthyans in the western Mediterranean: assemblages and biological parameters of their main species `, Mar. Freshw. Res. (2015). doi:10.1071/MF15093.

[29] F. Sardà, N. Bahamon, B. Molí, F. Sardà-Palomera, The use of a square mesh codend and sorting grids to reduce catches of young fish and improve sustainability in a multispecies bottom trawl fishery in the, Sci. Mar. 70 (2006) 347-353. doi:10.3989/scimar.2006.70n3347.

[30] D. Wileman, R. Ferro, R. Fonteyne, R.B. Millar, Manual of methods of measuring the selectivity of towed fishing gears, Copenhagen, 1996.

[31] M.K. Broadhurst, Modifications to reduce bycatch in prawn trawls: a review and framework for development, Rev. Fish Biol. Fish. 10 (2000) 27-60.

[32] F. Colloca, M. Cardinale, F. Maynou, M. Giannoulaki, G. Scarcella, K. Jenko, J.M. Bellido, F. Fiorentino, Rebuilding Mediterranean fisheries: a new paradigm for ecological sustainability, Fish Fish. 14 (2013) 89-109. doi:10.1111/j.1467-2979.2011.00453.x.

[33] F. Sardà, M. Coll, J.J. Heymans, K.I. Stergiou, Overlooked impacts and challenges of the new European discard ban, Fish Fish. 16 (2015) 175-180. doi:10.1111/faf.12060.

[34] EC, Report from the Commission to the European Parliament and the Council on the implementation of Article 9.3 of Council Regulation (EC) No 1967/2006 concerning management measures for the sustainable exploitation of fishery resources in the Mediterranean Se, Brussels, 2012.

[35] Y. Aldebert, L. Recasens, Comparison of methods for stock assessment of European hake Merluccius merluccius in the Gulf of Lions (Northwestern Mediterranean), Aquat. Living Resour. 9 (1996) 13-22.

[36] J. Lleonart, F. Maynou, Fish stock assessments in the Mediterranean : state of the art, Sci. Mar. 67 (2003) 37-49. http://www.google.com/search?client=safari\&rls=eses\&q=Fish+stock+assessments+in+the+Mediterranean:+state+of+the+art\&ie=UTF8\&oе=UTF-8.

[37] F. Sardà, J. Lleonart, J.E. Cartes, An analysis of the population dynamics of Nephrops norvegicus ( L .) in the Mediterranean Sea *, Sci. Mar. 62 (1998) 135-143.

[38] M. Coll, I. Palomera, S. Tudela, F. Sardà, Trophic flows, ecosystem structure and fishing impacts in the South Catalan Sea, Northwestern Mediterranean, J. Mar. Syst. 59 (2006) 63-96. doi:10.1016/j.jmarsys.2005.09.001.

[39] D. Bănaru, C. Mellon-Duval, D. Roos, J.L. Bigot, a. Souplet, a. Jadaud, P. Beaubrun, J.M. Fromentin, Trophic structure in the Gulf of Lions marine ecosystem (north-western Mediterranean Sea) and fishing impacts, J. Mar. Syst. 111-112 (2013) 45-68. 
doi:10.1016/j.jmarsys.2012.09.010.

[40] X. Corrales, M. Coll, S. Tecchio, J.M. Bellido, Á.M. Fernández, I. Palomera, Ecosystem structure and fishing impacts in the northwestern Mediterranean Sea using a food web model within a comparative approach, J. Mar. Syst. 148 (2015) 183-199.

doi:10.1016/j.jmarsys.2015.03.006.

[41] M. Wurtz, Mediterranean Submarine Canyons: Ecology and Governance, 2012. http://www.iucn.org/mediterranean.

[42] C. Stefanescu, B. Morales-Nin, E. Massutí, Fish assemblages on the slope in the Catalan Sea (western Mediterranean) - influence of a submarine canyon, J. Mar. Biol. Assoc. UK. 74 (1994) 499-512.

[43] J. Cartes, J.B. Company, F. Maynou, Deep-water decapods crustacean communities in the northwestern Mediterranean - influence of submarine canyons and season, Mar. Biol. 120 (1994) 221-229.

[44] S. Tudela, F. Maynou, M. Demestre, Influence of submarine canyons on the distribution of the deep-water shrimp, Aristeus antennatus (risso, 1816) in the NW Mediterranean, Crustaceana. 76 (2003) 217-225. doi:10.1163/156854003321824567.

[45] H. Farrugio, A refugium for the spawners of exploited Mediterranean marine species: the canyons of the continental slope of the Gulf of Lions, in: M. Würtzm (Ed.), Mediterr. Submar. Canyons Ecol. Gov., IUCN, Gland, Switzerland and Málaga, 2012: p. 216.

[46] R. Froese, Keep it simple: three indicators to deal with overfishing. Ghoti papers Ghoti aims to serve as a forum for stimulating and pertinent ideas. Ghoti publishes succinct commentary and opinion that addresses important areas in fish and fisheries science. Ghoti, Fish Fish. 5 (2004) 86-91. doi:10.1111/j.1467-2979.2004.00144.x.

[47] G.D. Ardizzone, Sensitive and Essential Fish Habitats in the Mediterranean Sea, Rome, 2006.

[48] M. Sistiaga, B. Herrmann, E. Grimaldo, R.B. Larsen, I. Tatone, Effect of lifting the sweeps on bottom trawling catch efficiency: A study based on the Northeast arctic cod (Gadus morhua) trawl fishery, Fish. Res. 167 (2015) 164-173. doi:10.1016/j.fishres.2015.01.015.

[49] C.S. Rose, J.R. Gauvin, C.F. Hammond, Effective herding of flatfish by cables with minimal seafloor contact, Fish. Bull. 108 (2010) 136-144. <Go to ISI>://WOS:000277017600002.

[50] M. Gagnon, D. Cotton, G. Myre, M. Paré, Trials of Thyborøn 15VF doors on two ACPG shrimp trawlers, 2011.

[51] Anonymous, Mejora de la Eficiencia, la sostenibilidad y el beneficio de la flota pesquera de arrastre catalana, 2010.

[52] R. Khaled, D. Priour, J.Y. Billard, Cable length optimization for trawl fuel consumption reduction, Ocean Eng. 58 (2013) 167-179. doi:10.1016/j.oceaneng.2012.10.001.

[53] N. Bahamon, F. Sardà, P. Suuronen, Potential benefits from improved selectivity in the northwest Mediterranean multispecies trawl fishery, ICES J. Mar. Sci. 64 (2007) 757-760. doi:10.1093/icesjms/fsm052.

[54] P. Winger, S. Eayrs, C. Glass, Fish behaviour near bottom trawls, in: H. Pingguo (Ed.), Behav. Mar. Fishes Capture Process. Conserv. Challenges, Willey-Blackwell, Iowa, USA, 2010: p. 392.

[55] C. Ryer, A review of flatfish behaviour relative to trawls, Fish. Res. 90 (2008) 138-146.

[56] P. Suuronen, F. Sarda, The role of technical measures in European fisheries management and how to make them work better, (2007).

[57] J.R. Beddington, D.J. Agnew, C.W. Clark, Current problems in the management of marine fisheries., Science. 316 (2007) 1713-6. doi:10.1126/science.1137362. 
Highlights:

- A reduction of discards is achieved by a change in the mesh shape on the codend

- The change in vessel operation allowed an improvement of the cost-benefit

- Lighter gears and doors would allow a reduction on fuel consumption

- Mid-water doors would reduce both the impact on the bottom and fuel consumption

- Simple modifications can contribute to mitigate the ecological impacts of fisheries 
Table 1. Mean values ( standard error) of different parameters of the gears by depth strata during the fishing operations, measured with ITI (EXP1 and EXP3) and SCANMAR (EXP2) systems. The results of the Student $t$-test (ns: not significant; \pm : $p<0.05 ; * *: p<0.01 ; * * *: p<0.001$ ) are also shown. DO: door opening; VO: vertical opening; HO: horizontal opening; S: symmetry; n: number of hauls analysed; ST: F/V Sort de Taranet; B: F/V Berto. TRA: traditional net with $40 \mathrm{~mm}$ diamond cod-end and traditional doors; EXP: experimental net with $40 \mathrm{~mm}$ square cod-end and lighter doors; BD: bottom doors; MWD: mid-water doors.

\begin{tabular}{ccccccc}
\hline \multicolumn{7}{c}{ EXP1 } \\
\hline Depth (m) & Vessel & DO $(\mathrm{m})$ & $\mathrm{n}$ & VO $(\mathrm{m})$ & $\mathrm{n}$ & \multirow{2}{*}{-test } \\
\hline \multirow{2}{*}{$300-500$} & $\mathrm{~B}$ & $93.4 \pm 3.9$ & 13 & $3.4 \pm 0.1$ & 13 & \multirow{2}{*}{ ns } \\
\cline { 2 - 7 } & $\mathrm{ST}$ & - & - & $3.3 \pm 0.1$ & 14 & \\
\hline \multirow{2}{*}{$500-700$} & $\mathrm{~B}$ & $86.5 \pm 1.0$ & 12 & $4.6 \pm 0.2$ & 11 & \multirow{2}{*}{$* *$} \\
\cline { 2 - 6 } & $\mathrm{ST}$ & - & - & $3.7 \pm 0.1$ & 11 & \\
\hline
\end{tabular}

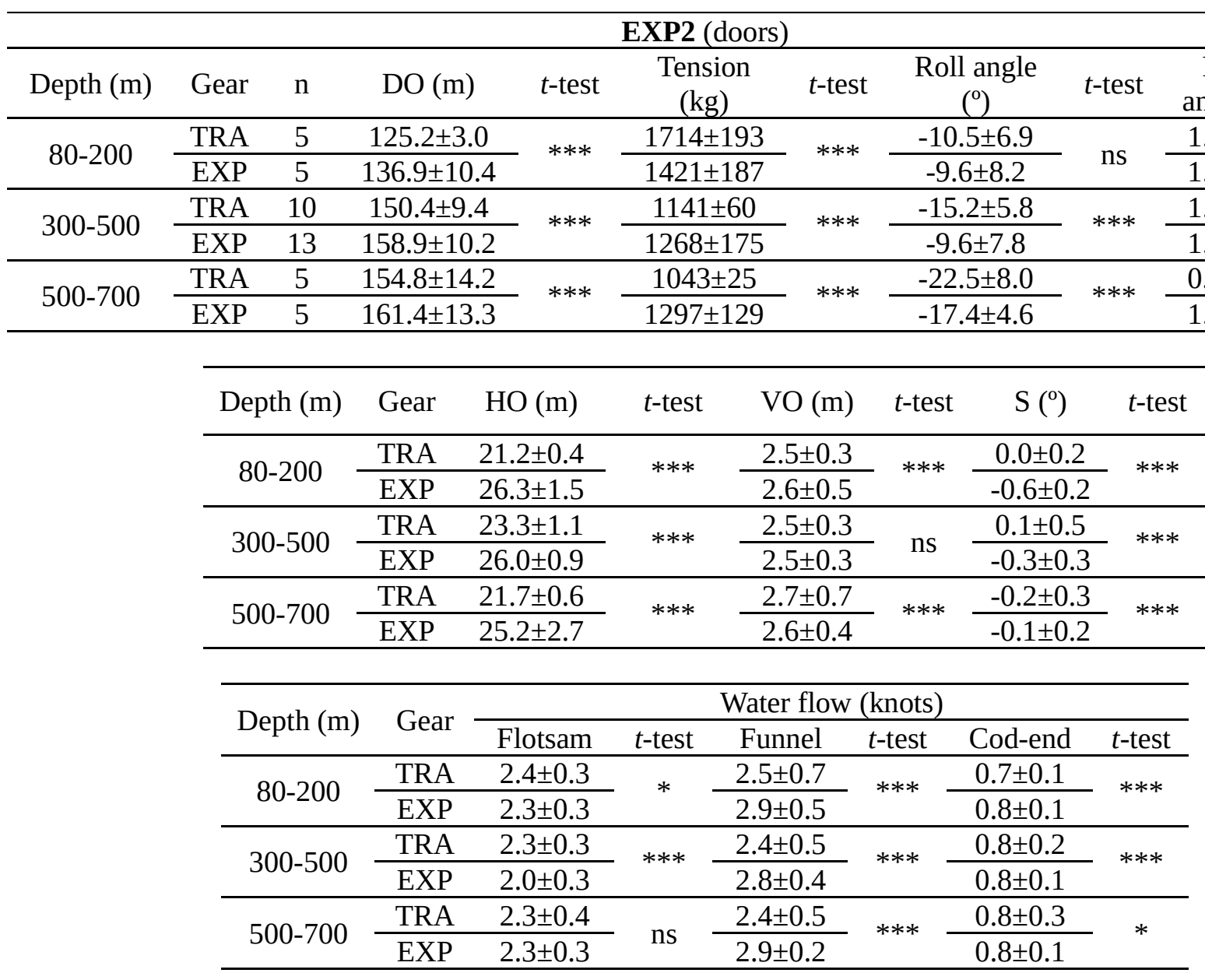

\begin{tabular}{|c|c|c|c|c|c|c|c|c|}
\hline \multicolumn{9}{|c|}{ EXP3 } \\
\hline Depth (m) & Doors & $\mathrm{n}$ & $\mathrm{DO}(\mathrm{m})$ & $t$-test & $\mathrm{HO}(\mathrm{m})$ & $t$-test & $\mathrm{VO}(\mathrm{m})$ & $t$-test \\
\hline \multirow{2}{*}{$120-160$} & $\mathrm{BD}$ & 8 & $98.1 \pm 2.6$ & \multirow{2}{*}{$* * *$} & $23.8 \pm 0.4$ & \multirow{2}{*}{ ns } & $1.3 \pm 0.1$ & \multirow{2}{*}{$* * *$} \\
\hline & MWD & 6 & $122.8 \pm 3.6$ & & $23.2 \pm 0.7$ & & $1.6 \pm 0.1$ & \\
\hline \multirow{2}{*}{$500-700$} & $\mathrm{BD}$ & 9 & $125.3 \pm 5.9$ & \multirow{2}{*}{$* *$} & $28.6 \pm 1.2$ & \multirow{2}{*}{ ns } & $3.4 \pm 0.2$ & \multirow{2}{*}{ ns } \\
\hline & MWD & 8 & $169.1 \pm 8.0$ & & $30.4 \pm 2.2$ & & $3.3 \pm 0.1$ & \\
\hline
\end{tabular}


Table 2. Mean abundance (number/h) and biomass (kg/h) for the commercial (COM), discarded (DISC) and total (TOT) catch and standard error, by bathymetric strata, for EXP1 (a), EXP2 (b) and EXP3 (c). Two-way ANOVA (EXP1; by vessel, V, and mesh shape in the codend, DI: $40 \mathrm{~mm}$ diamond; SQ: $40 \mathrm{~mm}$ square) and Student t-test (EXP2, by fishing gear TRA: traditional net with 40 mm diamond cod-end and traditional doors; EXP: experimental net with $40 \mathrm{~mm}$ square cod-end and lighter doors; EXP3, by type of doors BD: bottom doors and MWD: mid-water doors) results (ns: not significant; $*: p<0.05 ; * *: p<0.01 ; * * *: p<0.001$ ) are also shown (in EXP1, the combination $\mathrm{V}^{*} \mathrm{M}$ was never significant).

a)

\begin{tabular}{|c|c|c|c|c|c|c|c|}
\hline \multirow{3}{*}{ Depth (m) } & \multirow{3}{*}{ Catch } & \multicolumn{4}{|c|}{ number/h } & \multirow{2}{*}{\multicolumn{2}{|c|}{ t-test }} \\
\hline & & \multicolumn{2}{|c|}{ F/V Berto } & \multicolumn{2}{|c|}{ F/V Sort de Taranet } & & \\
\hline & & DI & SQ & DI & SQ & $\mathrm{V}$ & M \\
\hline \multirow{3}{*}{$300-500$} & $\mathrm{COM}$ & $272 \pm 96$ & $187 \pm 76$ & $202 \pm 83$ & $417 \pm 147$ & $*$ & ns \\
\hline & DISC & $811 \pm 287$ & $697 \pm 285$ & $1130 \pm 461$ & $456 \pm 161$ & ns & $*$ \\
\hline & TOT & $2205 \pm 263$ & $1652 \pm 274$ & $2809 \pm 523$ & $1745 \pm 282$ & ns & $*$ \\
\hline \multirow{3}{*}{$500-700$} & $\mathrm{COM}$ & $384 \pm 157$ & $776 \pm 347$ & $505 \pm 226$ & $323 \pm 132$ & ns & ns \\
\hline & DISC & $1007 \pm 411$ & $370 \pm 166$ & $655 \pm 293$ & $406 \pm 166$ & ns & ns \\
\hline & TOT & $2175 \pm 403$ & $2096 \pm 384$ & $1895 \pm 377$ & $1312 \pm 170$ & ns & ns \\
\hline Depth (m) & Catch & \multicolumn{4}{|c|}{$\mathrm{kg} / \mathrm{h}$} & \multicolumn{2}{|c|}{ t-test } \\
\hline \multirow{3}{*}{$300-500$} & $\mathrm{COM}$ & $98.6 \pm 18$ & $80.3 \pm 12.7$ & $117.6 \pm 9$ & $113.2 \pm 25.1$ & ns & ns \\
\hline & DISC & $31.8 \pm 11.3$ & $28.5 \pm 11.6$ & $43.9 \pm 17.9$ & $38.5 \pm 13.6$ & ns & $\mathrm{ns}$ \\
\hline & TOT & $151.3 \pm 16.5$ & $121.5 \pm 20.8$ & $182 \pm 22$ & $168.1 \pm 31.2$ & ns & $\mathrm{ns}$ \\
\hline \multirow{3}{*}{$500-700$} & $\mathrm{COM}$ & $71.6 \pm 11.1$ & $95.6 \pm 10.2$ & $99.6 \pm 20.3$ & $61.6 \pm 11.8$ & ns & $\mathrm{ns}$ \\
\hline & DISC & $28.1 \pm 11.5$ & $24.9 \pm 11.1$ & $23.8 \pm 10.7$ & $36 \pm 14.7$ & ns & $\mathrm{ns}$ \\
\hline & TOT & $142.5 \pm 20.7$ & $165 \pm 18.9$ & $175.7 \pm 22.6$ & $131.3 \pm 24.7$ & ns & ns \\
\hline
\end{tabular}

b)

\begin{tabular}{|c|c|c|c|c|c|c|c|}
\hline \multirow{2}{*}{ Depth (m) } & \multirow{2}{*}{ Catch } & \multicolumn{2}{|c|}{ number/h } & \multirow{2}{*}{$t$-test } & \multicolumn{2}{|c|}{$\mathrm{kg} / \mathrm{h}$} & \multirow[t]{2}{*}{$t$-test } \\
\hline & & TRA & EXP & & TRA & EXP & \\
\hline \multirow{3}{*}{$80-200$} & $\mathrm{COM}$ & $2058 \pm 74$ & $3155 \pm 1422$ & ns & $86.0 \pm 2.5$ & $160.2 \pm 60.3$ & ns \\
\hline & DISC & $1906 \pm 754$ & $1924 \pm 358$ & ns & $36.7 \pm 7.3$ & $45.3 \pm 6.3$ & ns \\
\hline & TOT & $3964 \pm 721$ & $5079 \pm 1385$ & ns & $122.7 \pm 7.5$ & $205.5 \pm 58.8$ & ns \\
\hline \multirow{3}{*}{$300-500$} & $\mathrm{COM}$ & $841 \pm 55$ & $508 \pm 30$ & $* * *$ & $28.5 \pm 1.7$ & $23.4 \pm 1.9$ & ns \\
\hline & DISC & $1923 \pm 521$ & $679 \pm 131$ & $*$ & $33.9 \pm 5.1$ & $16.8 \pm 8.9$ & ns \\
\hline & TOT & $2764 \pm 504$ & $1187 \pm 141$ & $* * *$ & $62.4 \pm 5.3$ & $40.3 \pm 9.9$ & ns \\
\hline \multirow{3}{*}{$600-700$} & $\mathrm{COM}$ & $426 \pm 57$ & $427 \pm 87$ & $\mathrm{~ns}$ & $16.2 \pm 1.9$ & $34.8 \pm 10.9$ & ns \\
\hline & DISC & $261 \pm 46$ & $292 \pm 53$ & ns & $7.4 \pm 0.7$ & $9.5 \pm 1.9$ & ns \\
\hline & TOT & $688 \pm 56$ & $719 \pm 129$ & $\mathrm{~ns}$ & $23.6 \pm 2.2$ & $44.3 \pm 12.8$ & $\mathrm{~ns}$ \\
\hline
\end{tabular}

c)

\begin{tabular}{|c|c|c|c|c|c|c|c|}
\hline \multirow{2}{*}{ Depth (m) } & \multirow{2}{*}{ Catch } & \multicolumn{2}{|c|}{ number/h } & \multirow{2}{*}{$t$-test } & \multicolumn{2}{|c|}{$\mathrm{kg} / \mathrm{h}$} & \multirow{2}{*}{$t$-test } \\
\hline & & $\mathrm{BD}$ & MWD & & $\mathrm{BD}$ & MWD & \\
\hline \multirow{3}{*}{$120-160$} & COM & $508 \pm 53$ & $347 \pm 55$ & * & $50.9 \pm 3.2$ & $41.9 \pm 4.8$ & ns \\
\hline & DISC & $1877 \pm 592$ & $1795 \pm 411$ & ns & $39.3 \pm 3.5$ & $46.4 \pm 8.4$ & ns \\
\hline & TOT & $2384 \pm 581$ & $2142 \pm 430$ & ns & $88.3 \pm 12.2$ & $90.2 \pm 5.6$ & ns \\
\hline \multirow{3}{*}{$500-700$} & $\mathrm{COM}$ & $1358 \pm 106$ & $1084 \pm 66$ & * & $21.9 \pm 1.7$ & $22.1 \pm 0.8$ & ns \\
\hline & DISC & $168 \pm 17$ & $187 \pm 23$ & $\mathrm{~ns}$ & $8.6 \pm 1.2$ & $7.3 \pm 1.0$ & ns \\
\hline & TOT & $1526 \pm 109$ & $1271 \pm 56$ & * & $30.5 \pm 2.6$ & $29.7 \pm 1.3$ & ns \\
\hline
\end{tabular}


Table 3. a) EXP1. Mean global estimations and standard error, by vessel and period, of fuel cost in relation to the first sale value (Cost/sales, \%€) and fuel consumption in relation to landings in terms of first sale value (Fuel/value, l/€). b) EXP2. Mean values and standard error, by gear (TRA: traditional net with $40 \mathrm{~mm}$ diamond cod-end and traditional doors; EXP: experimental net with $40 \mathrm{~mm}$ square cod-end and lighter doors) and strata, of fuel consumption by hour $(\mathrm{l} / \mathrm{h})$ and fuel consumption in relation to landings in terms of first sale value $(l / €)$. c) EXP3: Mean values and standard error, by gear (BD: bottom doors; MWD: mid-water doors) and strata, of fuel consumption by hour (l/h) and fuel consumption in relation to landings in terms of first sale value $(1 / €)$. The results of the Student $t$-test (ns: not significant; $*: p<0.05 ; * *: p<0.01 ; * * *: p<0.001$ ) are also shown.

a)

\begin{tabular}{lcccc}
\hline & Vessel & 2006 & 2007 & t-test \\
\hline \multirow{2}{*}{ Cost/sales (\%€) } & $F / V$ Berto & $61.6 \pm 16.1$ & $35.5 \pm 20.3$ & $*$ \\
\cline { 2 - 5 } & $F / V$ Sort de Taranet & $43.1 \pm 13.2$ & $26.8 \pm 9.8$ & $*$ \\
\hline \multirow{2}{*}{ Fuel/value (l/€) } & $F / V$ Berto & $1.21 \pm 0.32$ & $0.70 \pm 0.40$ & $*$ \\
\cline { 2 - 5 } & $F / V$ Sort de Taranet & $0.85 \pm 0.26$ & $0.53 \pm 0.19$ & $*$ \\
\hline
\end{tabular}

b)

\begin{tabular}{ccccc}
\hline & Stratum & TRA & EXP & t-test \\
\hline \multirow{3}{*}{$1 / \mathrm{h}$} & Deep shelf & $65.3 \pm 4.1$ & $60.4 \pm 9.4$ & ns \\
\cline { 2 - 5 } & Upper slope & $64.2 \pm 1.3$ & $60.8 \pm 1.5$ & $* *$ \\
\cline { 2 - 5 } & Middle slope & $60.4 \pm 5.1$ & $53.6 \pm 4.7$ & $* *$ \\
\hline \multirow{3}{*}{$1 / €$} & Deep shelf & $0.29 \pm 0.01$ & $0.18 \pm 0.08$ & $*$ \\
\cline { 2 - 5 } & Upper slope & $0.28 \pm 0.06$ & $0.28 \pm 0.18$ & ns \\
\cline { 2 - 5 } & Middle slope & $0.21 \pm 0.05$ & $0.2 \pm 0.03$ & ns \\
\hline
\end{tabular}

c)

\begin{tabular}{ccccc}
\hline & Stratum & BD & MWD & t-test \\
\hline \multirow{3}{*}{$1 / h$} & Deep shelf & $\begin{array}{c}43.76 \pm 3.3 \\
9\end{array}$ & $\begin{array}{c}38.46 \pm 2 . \\
85\end{array}$ & ns \\
\cline { 2 - 5 } & \multirow{2}{*}{ Middle slope } & $\begin{array}{c}48.03 \pm 2.1 \\
4\end{array}$ & $\begin{array}{c}45.73 \pm 1 . \\
36\end{array}$ & \multirow{2}{*}{ ns } \\
\hline \multirow{3}{*}{$1 / €$} & \multirow{2}{*}{ Deep shelf } & $0.21 \pm 0.04$ & $\begin{array}{c}0.23 \pm 0.0 \\
8\end{array}$ & $*$ \\
\cline { 2 - 5 } & \multirow{2}{*}{ Middle slope } & $0.16 \pm 0.04$ & $\begin{array}{c}0.18 \pm 0.0 \\
3\end{array}$ & $*$ \\
& & & $*$ \\
& & & & \\
\hline
\end{tabular}




\section{FIGURE CAPTIONS}

Figure 1. Map of the sampled areas off the north-western Mediterranean: Gulf of Lions (EXP1) and Balearic Islands (EXP2 and EXP3). Sampling stations are shown as black dots. Isobaths 200, 400, 500, 800, 1000 and $2000 \mathrm{~m}$ are shown.

Figure 2. EXP1: Redundancy analysis for the discarded catch composition, as abundance (n/h) in the upper (300-500 m, up) and middle slope (500-700 m, middle) by mesh shape (DI: $40 \mathrm{~mm}$ diamond mesh; SQ: $40 \mathrm{~mm}$ square mesh) and for the commercial catch composition as abundance (n/h) in the upper slope (300-500 m, bottom) by vessel (B: Berto; ST: Sort de Taranet). The variability explained by each model (as percentage) is also included. Aa: Aristeus antennatus; As: Argentina shyraena; Ca: Capros aper; Cc: Caelorhinchus caelorhincus; Es: Etmopterus spinax; Ga: Gadiculus argenteus; Gm: Galeus melastomus; Hd: Helicolenus daptylopterus;Hi: Hymenocephalus italicus; Lb: Lepidorhombus boscii; Lc: Lepidopus caudatus; Lp: Lophius piscatorius; Md: Molva dypterigia; Mm: Merluccius merluccius; Mp: Micromesistius poutassou; Mt: Macropipus tuberculatus: Ne: Nezumia aequalis; Nn: Nephrops norvegicus; Pb: Phycis blennoides; Pt: Polycheles typhlops; Rc. Raja clavata; Tl: Trigla lyra; Ts: Trachyrinchus scabrous.

Figure 3. EXP2: Redundancy analysis for the commercial (up) and discarded (down) catch composition, as abundance $(\mathrm{n} / \mathrm{h})$ in the upper slope (300-500 m) by mesh type (TRA: traditional net with $40 \mathrm{~mm}$ diamond cod-end and traditional doors; EXP: experimental net with $40 \mathrm{~mm}$ square codend and lighter doors). The variability explained by each model (as percentage) is also included. As: Argentina sphyraena; Ca: Capros aper; Cc: Caelorinchus caelorhincus; Ch: Chlorophthalmus agassizi; Es: Etmopterus spinax; Ga: Gadiculus argenteus; Gm: Galeus melastomus; Hi: Hymenocephalus italicus; Lb: Lepidorhombus boscii; Mm: Merluccius merluccius; Mp: Micromesistius poutassou; Mt: Macropipus tuberculatus; Mu: Munida spp; Nn: Nephrops norvegicus; Pb: Phycis blennoides; Pg: Plesionika giglioli; Ph: Plesionika heterocarpus; Pl: Parapenaeus longirostris; Pm: Plesionika martia; Sc: Scyliorhinus canicula; Sp: Synchiropus phaeton; Tt: Trachurus trachurus.

Figure 4. EXP3: Redundancy analysis for the abundance (n/h) of the commercial catch in the deep shelf (120-160 m, up), the commercial (middle) and discarded (down) catch in the middle slope (500$700 \mathrm{~m}$ ), showing the effect of depth (D) and gear type (G; BD: bottom doors; MWD: mid-water doors). The variability explained by each model (as percentage) is also included. Aa: Aristeus antennatus; Bs: Bathypolypus sponsalis; Cc: Chelidonichthys cucucus; Co: Conger conger; Ec: Eledone cirrhosa; Es: Etmopterus spinax; Ge: Geryon longipes; Gl: Glossanodon leioglossus; Gm: Galeus melastomus; Hi: Hymenocephalus italicus; Lb: Lepidorhombus boscii; Le: Lepidopus caudatus; Lc: Lampanictus crocodilus; Lf: Loligo forbessi; Md: Molva dypterigia; Mb: Mullus barbatus; Mm: Merluccius merluccius; Mo: Mora moro; Mp: Micromessistius poutassou; Ms: Mullus surmuletus; Na: Nezumia aequalis; Nn: Nephrops norvegicus; Pb: Phycis blennoides; Pm: Plesionika martia; Pa: Pasiphaea multidentata; Rc: Raja clavata; Sb: Stomias boa; Sc: Scyliorhinus canicula; Tl: Trigla lyra; Ts: Todarodes sagittatus; Tt: Trachurus trachurus; Us: Uranoscopus scaber; Zf: Zeus faber.

Figure 5. Evolution of mean fuel consumption (l/day, error bars are standard error) of the bottom trawler which carried out EXP3 from the second quarter of 2008 to the last quarter of 2014. Arrow 1 points the beginning of the implementation of fuel saving measures (reduction of boat speed when sailing to fishing grounds and a change of gear netting to low the drag coefficient). Arrows 2 point the beginning of EXP3 and the end of the adjustments in the gear after the implementation of mid-water 
doors until the current settings were achieved (a weight reduction of the in-line chain and the reduction of the sweeps' length).

Figure 6. Evolution of the efficiency (upper plot; l/€: 1 of fuel/€ benefit) and fuel consumption (lower plot; 1/day) of the bottom trawler which carried out EXP3 from January (1) to December (12), for the years 2009 (black symbols) and 2012 (white symbols). Asterisks in the lower over each month between March (3) and December indicate the results of the t-test comparing mean monthly values. 


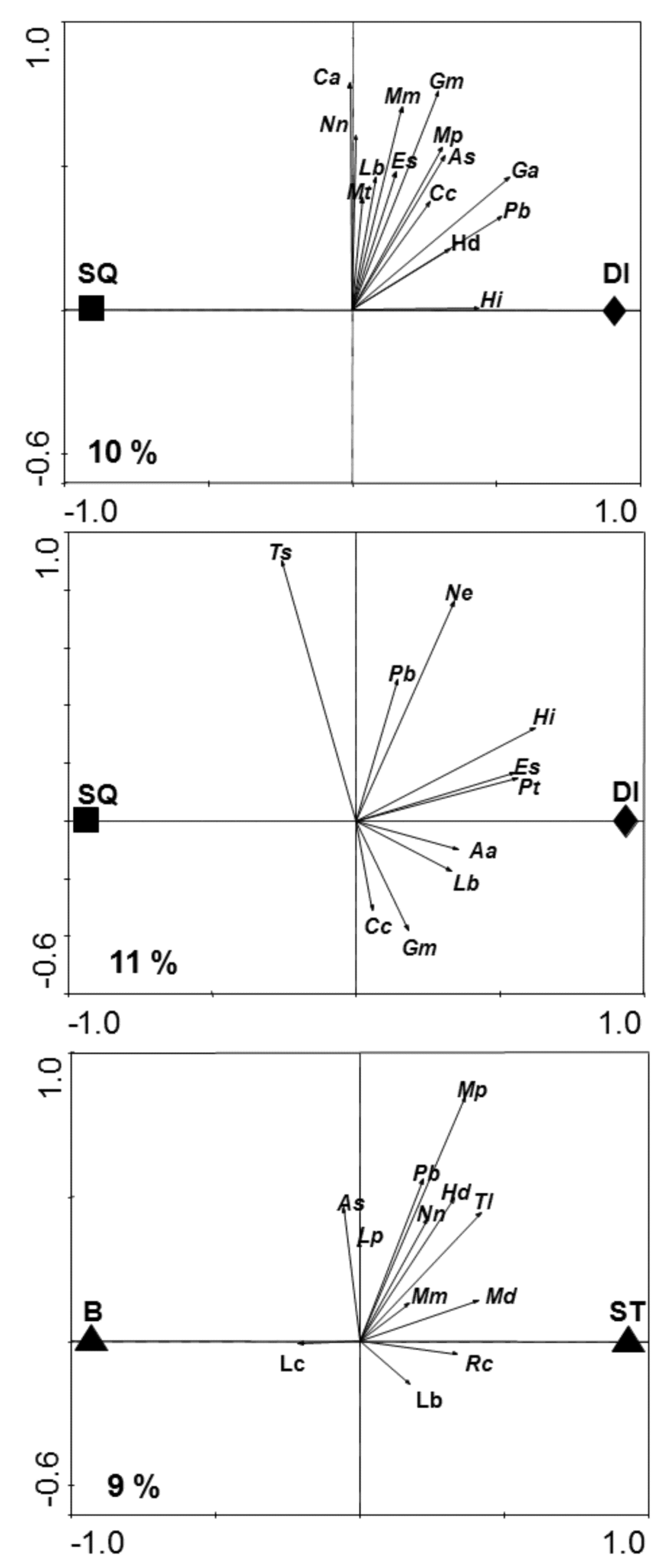



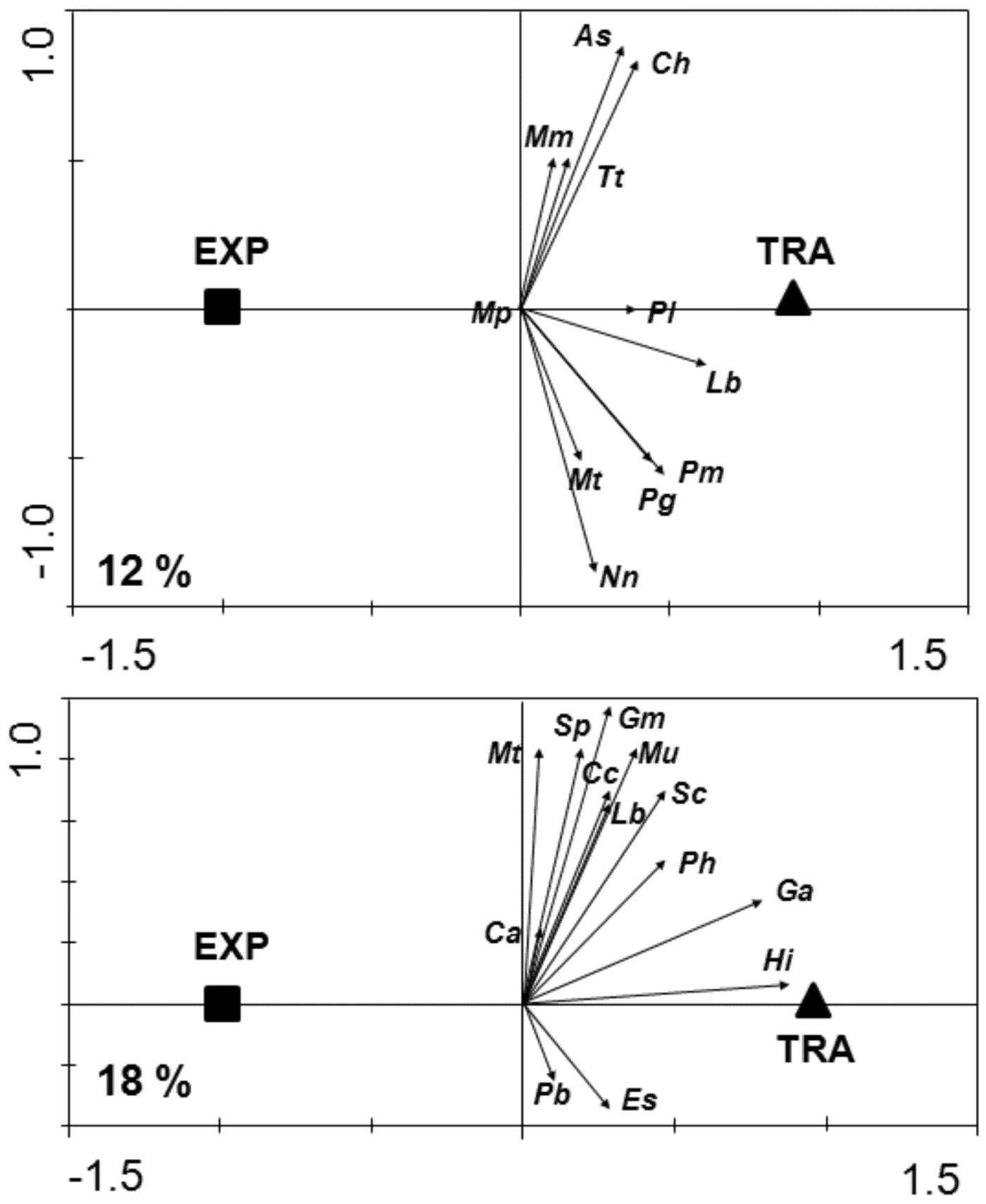

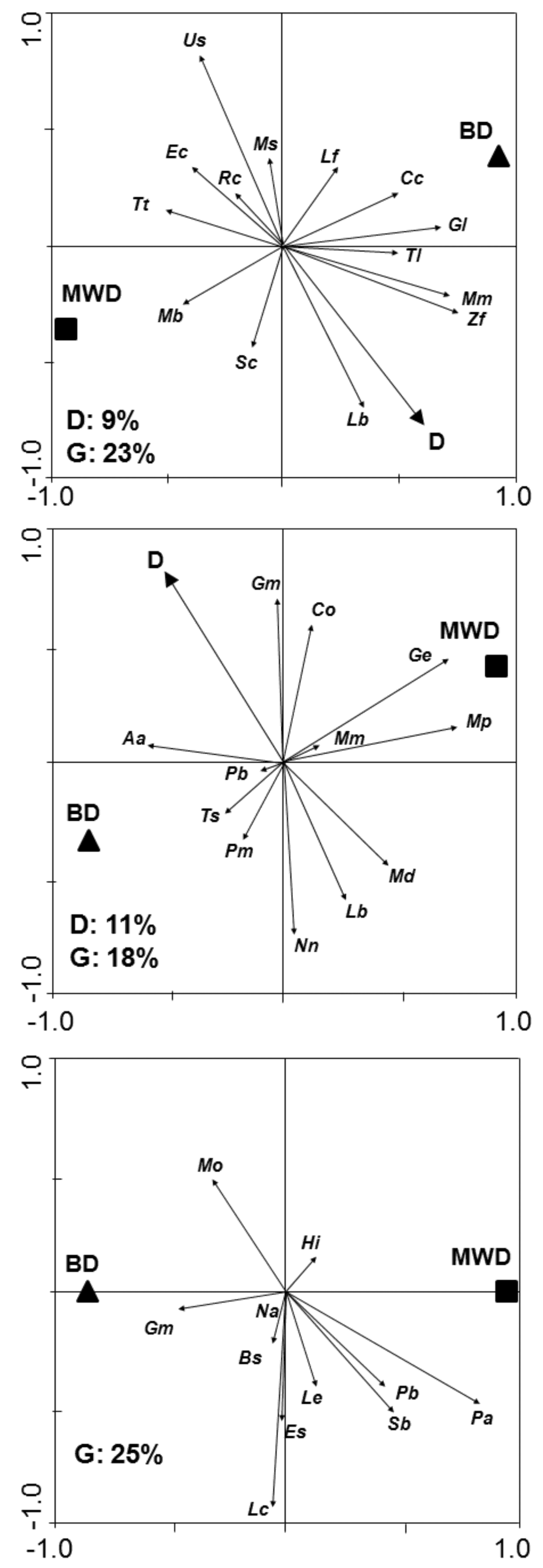


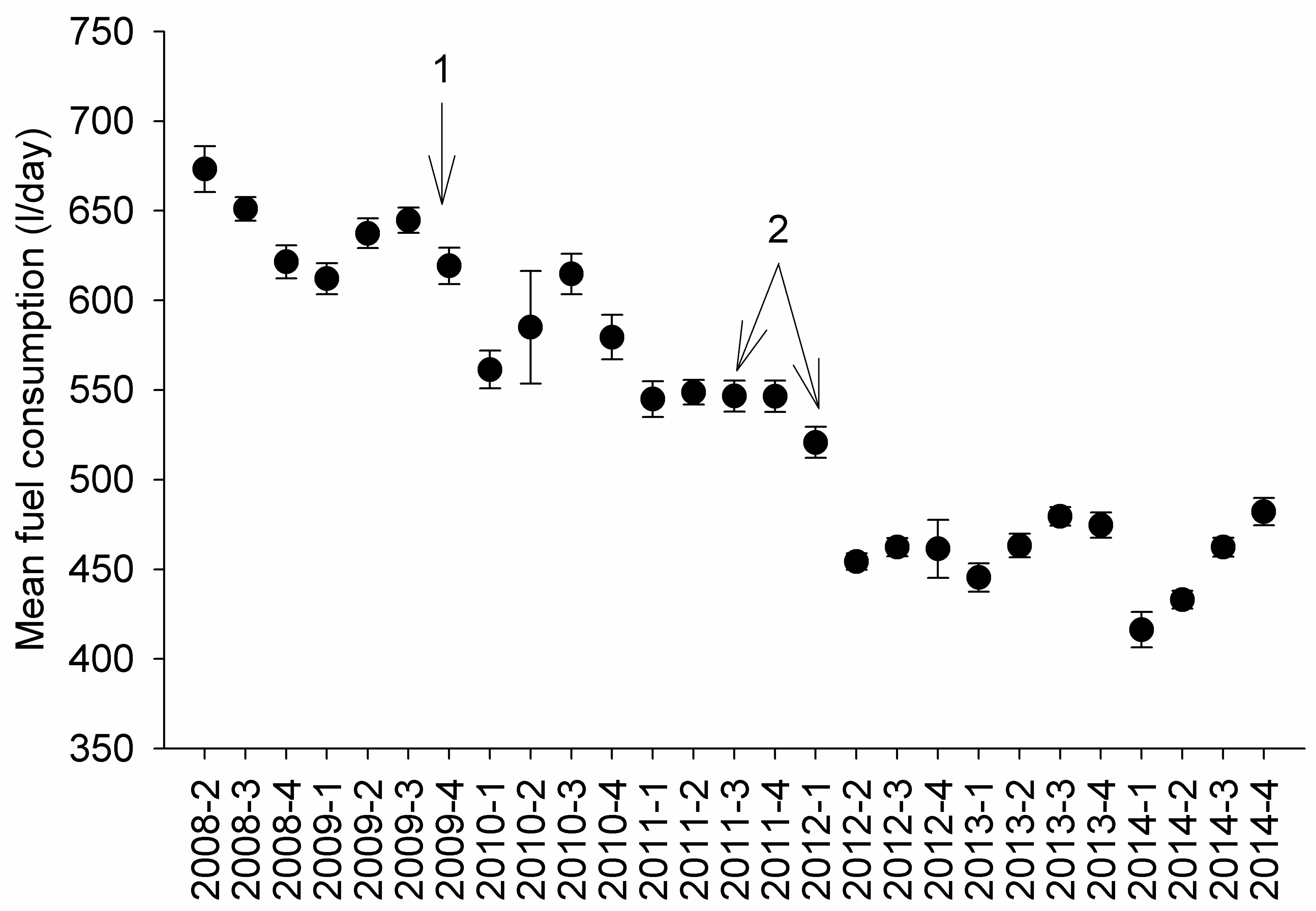

Quarter of the year 

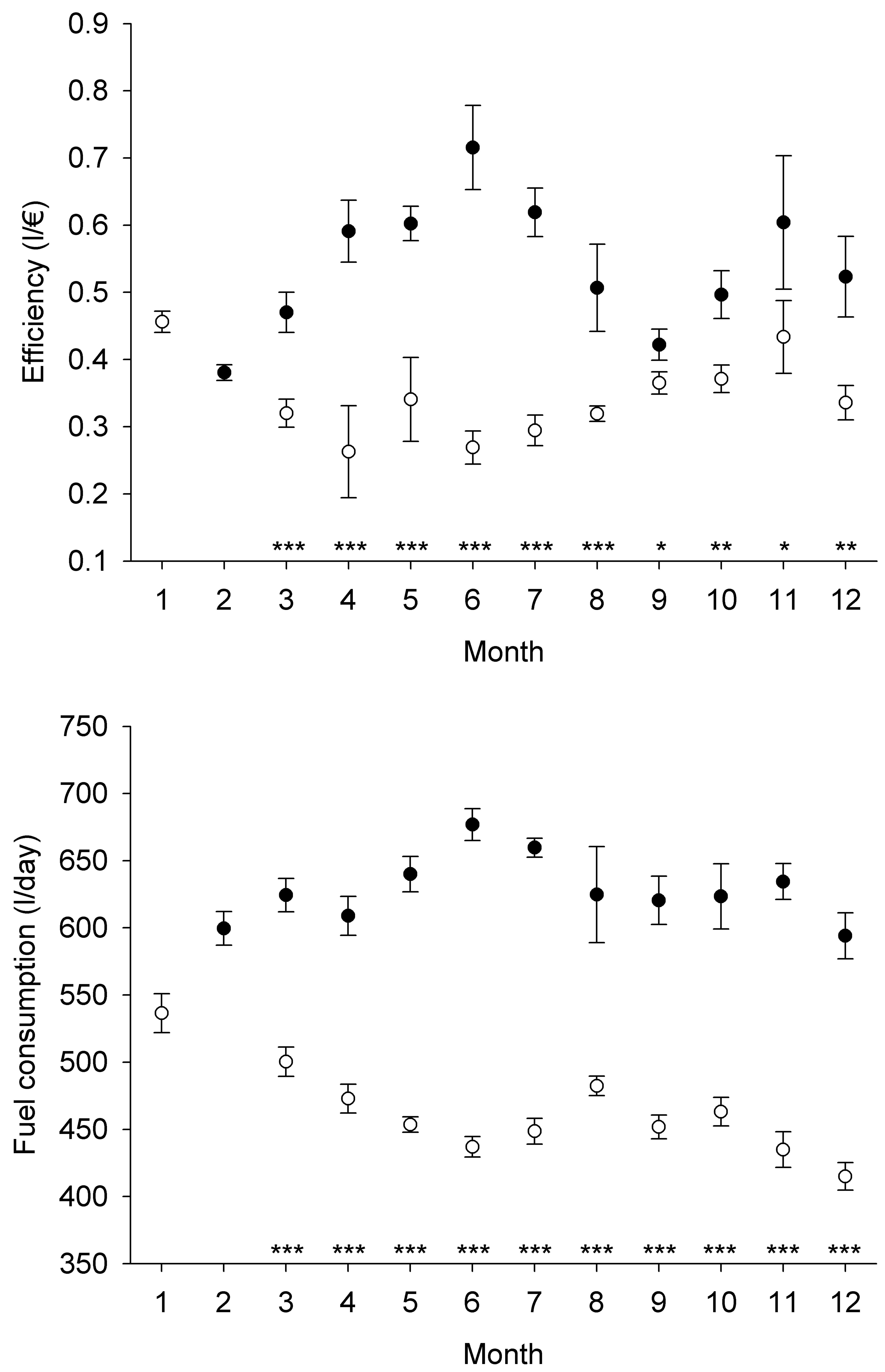